\title{
Feasible Strategies for Oral English Teaching
}

\author{
Guan Jian \\ School of Foreign Languages, Jilin Agricultural University, Changchun, Jilin 130118
}

\begin{abstract}
Nowadays, although the college students' enthusiasm for oral English learning has increased, their oral English proficiency is far from satisfactory. In order to explore the problems and barriers in the oral English teaching and to find the feasible teaching strategies for efficient oral English learning, the author made this study. According to the data collected from the qualitative and quantitative researches done by the author, there are four major problems existing: 1) Lack of language environment; 2) Lack of vocabulary (cannot talk in a native way); 3) Insufficient opportunities to talk in class (motivation in teachers' aspect); 4) Insufficient oral English practicing (motivation in students' aspect).
\end{abstract}

Key words: oral English, teaching strategy, simultaneous interpretation, Push theory, Zero-Linkage theory

\section{INTRODUCTION}

For a long time, English teaching to college students has been centered on reading, writing and listening. English speaking has been more or less neglected. However, with the advent of the new century, the need for proficient English speakers in many fields is increasing, which drives both English teachers and students to pay more attention to oral English than before. Although the enthusiasm for oral English learning has increased, the oral English proficiency of college students is far from satisfactory.

As is known to all, due to the limitation of China's examoriented educational system, teachers of English have to put more emphasis on vocabulary and grammar in the basic education, which leads to a well-trained exam-taking ability for students. When applauding for the great achievement made in vocabulary and grammar teaching, the side effects of the exam-oriented teaching methodology have to be admitted: a large number of students, who obtain large vocabulary database and precise grammatical structures, sit as a dummy in putting their knowledge in the conversation. That is what we call "Mute English". The need from various fields of the society makes this weakness outstanding.

Although more and more people start to realize the importance and usefulness of oral English in their daily life and work, it is really hard to find an easy solution for them to rapidly improve their speaking ability. Formulized English teaching methods in the traditional educational system exhaust students' learning interests. Money-oriented out-ofschool oral English trainings coated with a fancy cover give students hope, but eventually make them disappointed. In fact, current situation makes students lose their way in the search of feasible solutions in their learning of oral English.
In order to explore the problems and barriers in the oral English teaching and learning and to find the feasible

teaching strategies for efficient oral English learning, the author made a study of the traditional and current English teaching methodology. Generally, the dominant English teaching methods at home and abroad are Translation Approach, Direct Approach, Audio-lingual Approach and Communicative Approach (Kelly 1969, Canale \& Swain 1980, Littlewood 1981, Richard \& Rodgers 1986, Johnson 2002). Although they contribute a lot to English teaching and learning in their own ways, each of them has its weakness, which limits the efficiency of the oral English teaching and learning: Translation approach focuses on grammar and vocabulary teaching and teaches receptive skill prior to productive skill, which decreases students' studying interest. The direct approach emphasizes one's experience and overestimates the self-discipline of the learner. The audiolingual approach is sentence-pattern oriented in teaching, which is too mechanical and which neglects people's initiative and intelligence in the language learning. And the communicative approach uses the function-oriented teaching material, which breaks the traditional grammatical system and adds the difficulty to syntax teaching.

In addition to the limitation of each of the English teaching methods, lack of vocabulary, no language environment, insufficient opportunities to speak, nervousness when speaking in public etc, are common problems for students in oral English learning. When speaking English, students are asked to think in English in order to establish a virtual language environment. However, in the author's opinion, this widely accepted concept disarranges students' thinking and makes them struggle in oral English learning. That is because the way people think is related to all these elements: the culture, history, politics, economy, custom, society and national spirit of the language. Growing up and studying in a Chinese environment, without enough background knowledge and language ability, thinking in English for Chinese learners of English is impossible and could only increase the difficulty in oral English learning.

On the basis of the analysis of the traditional English teaching methods and the data collected from the qualitative and quantitative surveys, combined with the personal simultaneous interpreting experience, the author proposes several feasible strategies that might be helpful to oral English in a practical and effective way.

\section{RESEARCH METHODOLOGY}

In order to obtain a clear view of existing barriers in the oral English teaching and the problems students come across during the process of their oral English learning, both 
qualitative and quantitative methods are used in this study. The qualitative method is executed in the first phase by the form of focus group discussion (FGD). And the quantitative method follows up in the second phase as a data collection of the previous qualitative study.

\section{A. Qualitative research and Quantitative research}

Qualitative research involves methods of data collection and analysis that are non-quantitative (Lofland 1984). In other words, it focuses on "quality", a term referring to the essence or ambience of something (Berg 1989), or it involves a subjective methodology and you yourself are the research instrument (Adler 1987).

There are a variety of forms of study in the qualitative research such as FGD, in-depth interview, in-home visit, store checking etc. Qualitative research uses unreconstructed logic to get at what is really real -- the quality, meaning, context, or image of reality in which people actually do, not what they say they do (as on questionnaires). Unreconstructed logic means that there are no step-by-step rules, that researchers ought not to use prefabricated methods or reconstructed rules, terms, and procedures that try to make their research look clean and neat as in journal publications. Qualitative research methods are used primarily as a prelude to quantitative research

Quantitative research is "a formal, objective, systematic process in which numerical data are utilized to obtain information about the world" (Burns and Grove 1991). It is the systematic scientific investigation of properties and phenomena and their relationships.

The Following table is the comparison of the features between the quantitative approach and qualitative approach (Lofland 1984, Burns and Grove 1991).

A brief consideration of the major distinctions between quantitative research and qualitative research can help put both of the methodologies into context.

Both designs, quantitative and qualitative, are said to be systematic. Broadly speaking, quantitative research is objective whereas qualitative research often involves a subjective element. In gaining, analyzing, and interpreting quantitative data, the researcher can remain detached and objective. Often this is not possible with qualitative research where the researcher may actually be involved in the situation of the research.

Quantitative research is inclined to be deductive. In other words it tests theory. This is in contrast to the qualitative research, which tends to be inductive. In other words it generates theory.

Quantitative designs of research tend to produce results that can be generalized. The results of the quantitative study tend to hold true. Providing, of course, that the research is conducted in an appropriate manner using appropriate sampling techniques. However, qualitative studies tend to produce results that are less easy to generalize. This has to do with the problem of the sample used at the time. We all know, for example, that the words people choose for the compliment can change dependent on the particular set of circumstances. Even if we encounter the same people on another day, they may use a different word to express their compliment. So, it is difficult to generalize qualitative results.

Lastly here, the most obvious difference between quantitative research and qualitative research is that quantitative research uses data that are structured in the form of numbers or that can be immediately transported into numbers. If the data cannot be structured in the form of numbers, they are considered qualitative.

\section{B. Purpose of the survey}

A survey has been made to dig out all the barriers and problems students met during their oral English study, and then to quantify severity of the problems and barriers by the use of the detailed number and percentage. Some misunderstandings that students have taken as common sense in their oral English learning will also be put forward in the research.

\section{2.3 Execution of the research}

The whole survey is targeted at English major students. That is because they have experienced both traditional English teaching methods from primary school to senior high school and English-focused teaching methods in colleges and universities. This experience gives them the advantage to tell the difference between various English teaching methodologies.

Further, as English majors, they are the only targets that have the systematic oral English course in the university study. The stronger overall and oral English competence makes their opinions and perceptions more penetrating and in-depth than that of non-English majors. Therefore both qualitative and quantitative studies will be executed among English majors in this research.

Table 1. Comparison of Features of Quanti and Quali Approaches

Comparison of Features of Quanti and Quali Approaches

\begin{tabular}{|l|l|}
\hline Quantitative & Qualitative \\
\hline Both are systematic in their approach \\
\hline Objective & Subjective \\
\hline Deductive & Inductive \\
\hline Gerneralisable & Not gerneralisable \\
\hline Numbers & Words \\
\hline
\end{tabular}

The whole survey consists of 2 phases: one FGD to dig out all the potential problems and barriers in the oral English study and one quantitative questionnaire to quantify the severity of the problems and barriers.

\section{1) Qualitative study: FGD}

FGD, short form of Focus Group Discussion, is one of the qualitative researching forms. The group usually consists of one moderator and 4 to 8 qualified respondents. They will have a focused discussion based on certain topic. The moderator mainly acts as a question-raiser and tries to get the detailed answer by using various probing strategies, such as ranking, rating, personification etc. All the respondents in the group are asked to share their opinion freely without 
concerning about the right and wrong answers. Usually the whole discussion lasts around 2 hours.

FGD helps the researcher to find out detailed and indepth answers of each specific question raised in the Discussion Guide. It is also the precondition of quantitative research because all the findings in the FGD help the researcher to set up the guideline and questionnaire in the follow-up quantitative research.

In the first round of survey, 8 English major undergraduate students between grade two and grade three were invited to FGD. There were three male students and five female students, which is close to the gender ratio in the English Department.

The purpose of this FGD was to let students share their experience of oral English study and dig out the main problems and barriers they encountered during the studying process.

In the end of FGD, problems and barriers within oral English study were listed out as a checklist for the second round quantitative study.

\section{2) Quantitative study: Questionnaire}

The second round is a quantitative study in which 100 English major students from freshmen to postgraduate are interviewed. In order to find such a large number of English major students, the author held a lecture about simultaneous interpretation training and oral English learning in the English Department on October 25th. All the students were voluntary to attend the lecture and were asked to finish the questionnaire. Following is the grade and detailed number of students who took part in the quantitative research.

The purpose of this quantitative research was to do the data collection, analysis and processing based on the problems and barriers found in the previous round of FGD. By analyzing and quantifying the data collected in this round, we can find the prior barrier in the oral English study. Then in the next part of the paper, the author will focus on the top issue and propose the practical solutions for students.

\section{DATA ANALYSIS}

According to data, we can find that freshmen from both undergraduate and postgraduate are more interested in the oral English learning and simultaneous interpretation. There are 34 and 20 of them in the lecture respectively. Sophomore and junior students rank the third in term of number, which have both 15 participants in the lecture. There are also 7 senior students and 9 postgraduate grade two students.

Students who participated in the quantitative study were asked to do the rating of their overall English performance and oral English performance based on a 10-point scale--- 1 means "very poor" and 10 means "as good as native speaker". The average rating of overall English performance is 6.38. Most of the ratings fasten on range from 5 to 8. And from the detailed data, we can find that most of the rating 5 come from undergraduate freshmen. Therefore, the overall English performance of English major students is on the middle-to-high level. Comparatively speaking, students' oral English performance is a little poorer. The rating is 0.61 lower than that of overall English performance. This time, the rating range starts from 3 to 9 and the main range is between 4 and 8 . Based on these two ratings, we can conclude that students' average ability of writing, reading and listening is stronger than and speaking. The oral English ability hinders their overall English performance.

In the quantitative questionnaire, students are asked to do the ranking of ten statements in term of the severity in their own learning process. All these statements are the potential problems and barriers students mentioned in the FGD.

Compared with qualitative research, statement $\mathrm{G}$ (lack of foreign teachers) and statement $\mathrm{J}$ (unavailability of oral English classes) get the less vote in quantitative study, which have only 5 and 8 votes respectively.

\section{Statement A: Lack of language environment}

Statement A gets 71 votes from the students, which accounts for $24 \%$ of the total votes for top-3 problems. In the FGD, students defined the language environment as the culture and history of the target language, in which all the people are speaking and using the target language in their daily life. In fact, as the students mentioned, the best way to get in this language environment is to live in the English speaking countries. When the author probed deep about the cause of this mindset, almost all the students come out spontaneously with the saying "thinking in English when leaning English". They said that "if you want to think in an English way, you need be involved in an English environment. Otherwise, it's impossible to learn a good English, especially a good oral English". Although the students believe that just staying in china could also learn English well, it takes much longer time and zigzag way to achieve the success. They said, "Staying in English speaking country accelerates the learning process, for you have more opportunities to speak, listen and learn new words".

Statement B: Lack of vocabulary (cannot talk in a native way)

"Lack of vocabulary" is the common problem in the foreign language study. Without using the right words, no one can speak foreign language in the native way. Someone regards it as the most difficult problem and key barrier in language learning. However, according to the author's opinion, there is an easy solution. In the right way of training and practicing, students can master most of the useful and daily words, phrases, and even sentences that make the conversation smooth and colloquial within a very short time.

Statement C: Insufficient opportunities to talk in class Statement D: Insufficient oral English practicing

Actually, statement $\mathrm{C}$ and $\mathrm{D}$ are both addressing the motivation issue in the oral English learning. Statement $\mathrm{C}$ is taking about the motivation in the teachers' aspect while statement D is the motivation in the students' aspect. If we add up the votes of these two statements, the number reaches 103 , which occupies $34 \%$ of the total votes for top-3 problem. It seems that motivation is critically important in the oral English teaching and studying.

With the right motivation, On the one hand, teachers can help students to make full use of time in class and raise their interest in the overall English study. On the other hand, being clearly aware of the motivation, students will be strongminded in the whole learning process. It makes them 
persistent and brings them the courage to come over the difficulties they would come across.

\section{CONCLUSION}

The result of this study provides teachers with 5 practical oral English teaching strategies toward the problems and barriers found in the traditional and current oral English teaching.

The Push Theory reminds teachers the importance of the motivation in both students' and teachers' aspects, which works as a guideline to help students solve a variety of problems that they come across in different learning phases.

"Fluency-inclined strategy first and the accuracyinclined second" solves the controversy teachers face when choosing methods in oral English teaching.

The Interpretation Approach that establishes the direct linkage between oral English and interpretation totally overthrows people's conventional mindset about language environment issue in the oral English learning. And the ZeroLinkage Theory enlightens both teachers and students a new way of oral English speaking.

The awareness of the lexical chunks changes the students' traditional vocabulary learning habits because, other than the enlargement of the vocabulary, it also improves the communicative performance and competence. Therefore, the acquisition of lexical chunks can help the students to obtain the sense of the target language unconsciously.

Based on the benefits and strengths of the above that discussed oral English teaching strategies, it can be concluded that the combined use of these strategies does contribute to the efficiency of oral English study and the proper adjustment of the focus of them will accelerate improvement and achieve a rapid progress.

However, the feasible strategies proposed in the paper are mainly based on the combination of foreign language teaching theories and the author's personal simultaneous interpreting experience. They have not been validated by the real case study yet.

A new round of teaching research is required to execute between two classes of English major students. It is better to start with the senior students because they have mastered quite a good amount of vocabulary and grammar. The whole teaching process can last for one to two semesters. One class of the students is trained by the use of practical strategies suggested by the author. The other class still uses the current teaching methodology and it is regarded as the benchmark for the tested class.

In the end of the semester, the two classes of students can be assigned with the same whole range of oral English test. The data collected from two classes can be used in both quantitative and qualitative study again so as to find out the advantages and limitations of each strategy. Nevertheless, it should be pointed out that the efficiency of the strategy would vary depending on students' individual differences. Through the case study, we could optimize the feasibility of the proposed strategies and generate a combination of highly efficient and widely accepted oral English teaching methodology.

\section{REFERENCES:}

[1] Adler, P. \& P. (1987). Membership Roles in Field Research. Beverly Hills: Sage.

[2] Alderson, J. C. et al. (2000). Language Test Construction and Evaluation. Beijing: Foreign Language Teaching and Research Press.

[3] Altenberg, B. (1998). On the phraseology of spoken English: the evidence of recurrent word-combinations. In Cowie, A. P. (Ed.), Phraseology: Theory, Analysis and Applications. Oxford: Clarendon Press.

[4] Arnold, J. (2000). Affect in language learning. Cambridge: Cambridge University Press.

[5] Becker, J. (1975.) The phrasal lexicon. Cambridge Mass Boltand Newman.

[6] Berg, B. (1989). Qualitative Research Methods for the Social Sciences. Boston: Allyn \& Bacon.

[7] Brown, H. D. (2001). Teaching by principles: An interactive approach to language pedagogy. Beijing: Foreign Language Teaching and Research Press. 